\title{
Calidad bacteriológica del agua de cuatro balnearios del municipio de Valledupar (Colombia)
}

\author{
Ana Quintero-Corrales, Pedro J. Fragoso-Castilla* y Gino F. Olivieri \\ Universidad Popular del Cesar, Grupo de investigación Parasitología y Agroecología Milenio, Valledupar Cesar, \\ Colombia (correo-e: amquintero@unicesar.edu.co, pedrofragozo@unicesar.edu.co; ginoolivieri@unicesar.edu.co) \\ * Autor a quien debe ser dirigida la correspondencia.
}

Recibido Oct. 29, 2020; Aceptado Ene. 7, 2021; Versión final Mar.5, 2021, Publicado Ago. 2021

\begin{abstract}
Resumen
El objetivo del presente estudio fue establecer la contaminación bacteriológica de cuatro balnearios recreacionales cercanos a Valledupar (Colombia). Se tomaron 32 muestras durante los meses de octubre a diciembre del año 2014 y en enero del año 2015. La determinación del grupo coliformes se realizó mediante la técnica de filtración por membrana combinada con el método de sustratos cromogénicos (Merck). A nivel espacial no se presentaron diferencias significativas para los coliformes totales; pero si para el indicador de Escherichia coli. A escala temporal se presentaron diferencias significativas para coliformes totales y E. coli. No hubo correlación significativa entre las variables microbiológicas y fisicoquímicas. Las altas concentraciones de coliformes totales y $E$. coli se debe a la introducción de residuos de origen antropogénico en las zonas examinadas. Se concluye que las concentraciones de coliformes totales y $E$. coli en las aguas de los balnearios sobrepasan lo estipulado en la normatividad ambiental vigente para uso recreativo mediante contacto primario.
\end{abstract}

Palabras clave: aguas superficiales; calidad; coliformes; balneario; contaminación

\section{Bacteriological water quality for four recreational river spas in the municipality of Valledupar (Colombia)}

\begin{abstract}
The objective of the present research study was to examine the level of bacteriological contamination in four recreational river spas near Valledupar (Colombia). Thirty-two samples were collected from October to December 2014 and in January 2015. Quantification of coliforms was performed by the membrane filtration technique combined with the chromogenic substrates method (Merck). There were no significant differences for total coliforms counts at the spatial level, but differences were significant for Escherichia coli. On a temporal scale, there were significant differences for total coliforms and E. coli. In addition, there was no significant correlation between microbiological and physicochemical variables. Residues of anthropogenic origin in the study area most possibly caused the high concentrations of total coliforms and E. coli. In conclusion, the total coliform and $E$. coli concentrations observed in the recreational spas exceeded current environmental regulations for primary contact use.
\end{abstract}

Keywords: surface water; quality; coliforms; spa; pollution 


\section{INTRODUCCIÓN}

El desarrollo turístico de la región Caribe Colombiana, genera importantes indicadores de empleos y crecimiento económico. Sin embargo, la expansión de la infraestructura turística impacta negativamente sobre los ecosistemas acuáticos, lo cual se traduce en el deterioro o destrucción de los recursos naturales que alguna vez aportaron valor ecológico a la región (Barragán y De Andrés, 2016; Islam et al., 2018). Las aguas superficiales son un componente esencial de los ecosistemas acuáticos, por sus múltiples propiedades, son utilizadas en actividades tales como: la ganadería, la industria, la agricultura, uso doméstico y recreacional (Ustaoğlu et al., 2019); se constituye en un importante recurso para las actividades humanas, impactando directamente en el bienestar social y económico de las regiones (Fernández y Gutiérrez, 2013), también participan en la transmisión de agentes patógenos que son descargados a través de las heces.

Uno de los principales problemas qué presentan las aguas superficiales, como los ríos Guatapurí, Badillo y Candela en su cuenca alta es la inadecuada disposición de excretas por parte de los pueblos indígenas que habitan en la Sierra Nevada de Santa Marta - Colombia, los cuales realizan sus necesidades fisiológicas a cielo abierto y con la llegada de las lluvias son vehiculizadas hasta el cauce de los ríos. En la cuenca media de estos ríos la principal afectación es el turismo que trae consigo vendedores ambulantes y zonas de restaurantes, donde es perceptible el manejo inadecuado de los residuos sólidos y líquidos, que impactan negativamente a los sitios recreacionales, causando la contaminación del agua, suelo y por consiguiente un impacto visual del ambiente. Por otra parte, turistas y residentes realiza sus necesidades fisiológicas en los balnearios realizando el proceso de inmersión en las corrientes de los ríos, lo cual incrementa la posibilidad de propagación de algunas enfermedades infectocontagiosas.

Los procesos de monitoreo constituyen una importante estrategia para evaluar la calidad del agua. Los coliformes totales y los coliformes termotolerantes constituyen el grupo bacteriano más utilizado para evaluar la calidad microbiológica del agua destinada para el consumo humano, las aguas servidas y las aguas de recreación (Larrea-Murrell et al., 2013); Por su presencia en las heces, su fácil aislamiento y la posibilidad de que junto a ellos existan microorganismos patógenos; Los coliformes termotolerantes han sido utilizados por décadas como indicadores bacterianos, porque muestra una buena relación con las enfermedades transmitidas por aguas recreacionales (Korajkic et al., 2018); Debido a los altos costos y a la diversidad de microorganismo patógenos que se pueden encontrar en aguas contaminadas es preferible usar microorganismos indicadores o centinelas para el monitoreo y la regulación de aguas destinadas a diferentes usos.

Las bacterias de origen fecal entran a las aguas naturales desde una variedad de fuentes; plantas de potabilización, actividades agropecuarias tales como deposición de desechos animales, escurridos de lodos de tratamiento y escurridos urbanos pueden devolverse a los humanos por varias rutas como el uso de estas aguas para la recreación o deporte, para la irrigación de frutas o verduras y como agua para el consumo humano (Williamson et al., 2017). Esto ha dado lugar a diversos impactos económicos y ambientales que amenazan la permanencia de los recursos y los espacios naturales que contribuyen en la actividad turística (Ashbolt, 2015). La gastroenteritis y algunas enfermedades respiratorias agudas son asociadas con la recreación en aguas superficiales, contaminadas con bacterias de origen entérico (DeFlorio-Barker et al., 2018). Los datos con que se cuenta en la actualidad, indican qué, en los países tropicales, donde estas enfermedades son ya endémicas y la proporción de portadores es elevada, constituyen un importante problema de salud pública que amerita mayor atención por parte de las autoridades locales.

El presente trabajo de investigación se enfoca a establecer la contaminación bacteriológica de cuatro balnearios cercanos a la capital del Departamento del Cesar, mediante el uso del grupo coliforme y $E$ coli, con el fin de determinar el nivel de riesgo para la salud de los bañistas, debido a que estos sitios son visitados con frecuencia durante los fines de semana.

\section{MATERIALES Y MÉTODO}

Se describe el área de estudio, luego se describen las estaciones de muestreo y la toma de muestra, terminando con una explicación sobre el análisis de variables.

\section{Área de estudio}

El estudio se realizó en cuatro (4) balnearios turísticos del municipio de Valledupar, al norte del departamento del Cesar. El río Guatapurí nace en la jurisdicción del municipio de Valledupar, en la cara suroriental de La Sierra Nevada de Santa Marta, a una altura de 5.200 metros sobre el nivel del mar, desde su nacimiento hasta su desembocadura recorre 78 kilómetros, de los cuales 42 corresponden a la cuenca alta, 22 a la media y 14 a la baja; sus aguas son vertidas al río Cesar; su cuenca abarca aproximadamente 90 mil hectáreas y está 
formada por varios ríos, el Donachuí, Curiba, Mamanquea y Los Mangos. El río Badillo nace en el páramo de Curiba a 4.100 m.s.n.m. en la sierra nevada de Santa Marta, en su parte alta recibe el nombre de río Surivaca y se alimenta principal mente de los ríos Candela y Pontón; sus aguas son vertidas al río Cesar; por su parte el río Candela nace en las estribaciones de la sierra nevada de Santa marta y desemboca en el río Badillo.

El Rio Guatapurí se constituye la reserva hídrica natural de la región, teniendo usos diversos a lo largo de su extensión como: fuente de agua potable e industrial, irrigación de cultivos, así como recreación y esparcimiento de los habitantes de la ciudad de Valledupar ya que forma parte de su habitad urbana. Por el norte de Valledupar, se encuentra el balneario Hurtado, principal lugar de recreación y diversión de la capital del Cesar y uno de los lugares más contaminados del afluente, además el municipio cuenta con otros balnearios como el rincón, y al norte del municipio con la vega arriba (Rio Badillo) y el Mojao (Rio candela), los cuales también se han visto afectados debido a la descarga de desechos a estos ríos y la gran afluencia de visitantes que en los últimos años se ha incrementado.

\section{Selección de estaciones de muestreo}

Se seleccionaron 4 estaciones de muestreo en los ríos Guatapurí, Badillo y Candela: las cuales fueron seleccionadas y georreferenciadas (Figura 1).

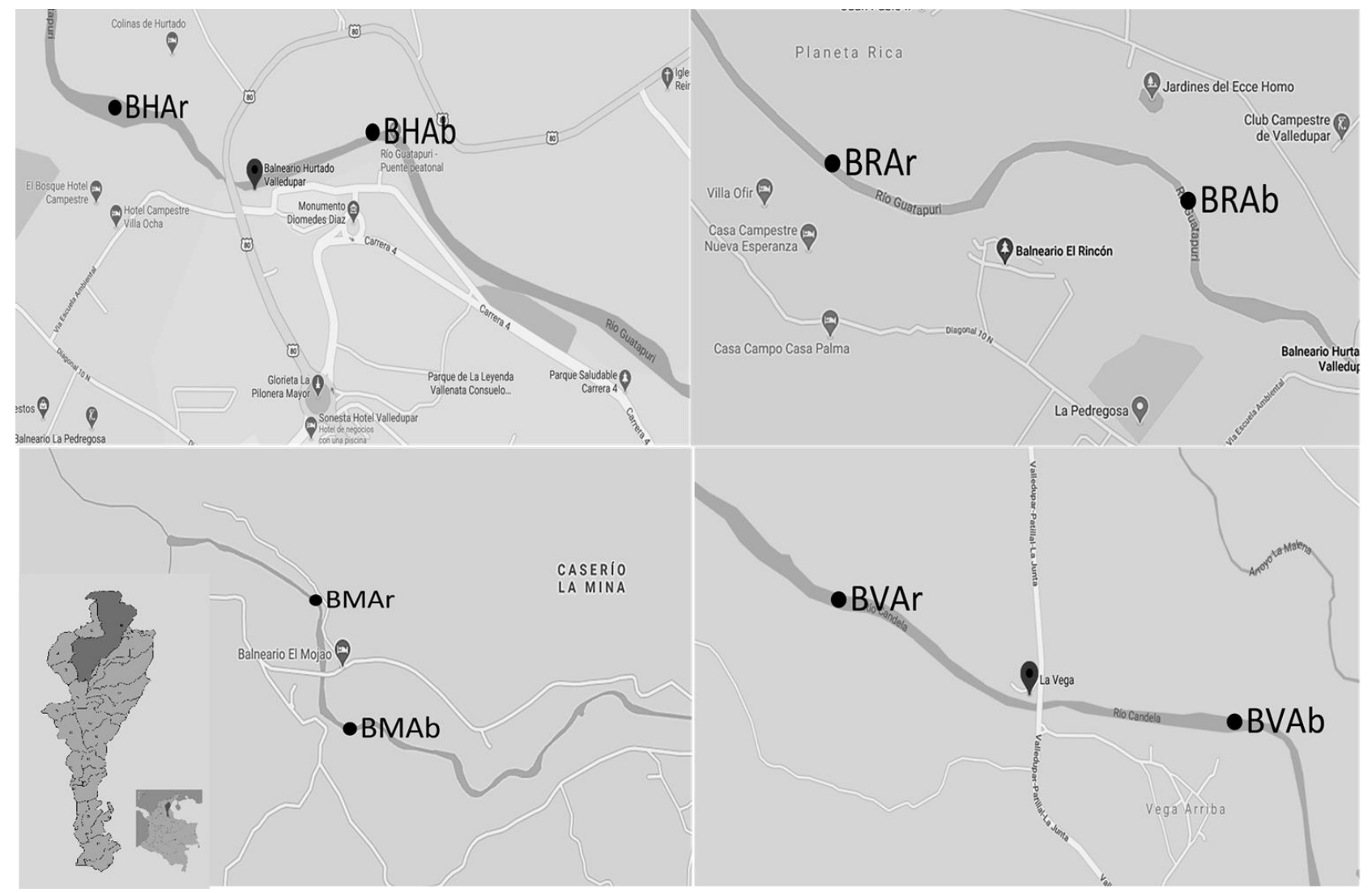

Fig. 1: Localización del área de estudio

\section{Fase de campo}

Se realizaron 32 muestreos durante los meses de octubre a diciembre de 2014 y enero de 2015, se establecieron ocho estaciones de muestreo en el río Guatapurí, río Badillo y río Candela las cuales fueron georreferenciadas, tomando tres replicas por cada punto de muestreo, las muestras fueron tomadas 500 metros aguas arriba y 500 metros aguas abajo del punto donde está establecido cada balneario (Tabla 1).

Las muestras de agua fueron tomadas con frascos de vidrios previamente esterilizados, con capacidad de $500 \mathrm{~mL}$, y se sumergieron a contra corriente a $30 \mathrm{~cm}$ de lámina de agua. Inmediatamente se rotularon con el sitio con fecha y hora; por cada estación se colectaron tres réplicas de $450 \mathrm{~mL}$ cada una y se refrigeraron a $4^{\circ} \mathrm{C}$ hasta ser transportadas al Laboratorio para Análisis de Aguas de la empresa de Servicios Públicos de la ciudad de Valledupar EMDUPAR S.A. E.S.P. 
Tabla 1. Ubicación de puntos de muestreo

\begin{tabular}{|c|c|c|c|}
\hline Código Estación & Puntos de Muestreo & Coordenadas & Sitio de Muestreo \\
\hline $\mathrm{BHAr}$ & Balneario Hurtado aguas arriba & $10^{\circ} 30^{\prime} 24.08 " \mathrm{~N}-73^{\circ} 16^{\prime} 43.44^{\prime \prime O}$ & \multirow{4}{*}{ Rio Guatapurí } \\
\hline $\mathrm{BHAb}$ & Balneario Hurtado aguas abajo & $10^{\circ} 29^{\prime} 51.04^{\prime \prime} \mathrm{N}-73^{\circ} 15^{\prime} 33.49^{\prime \prime O}$ & \\
\hline BRAr & Balneario Rincón aguas arriba & $10^{\circ} 30^{\prime} 21.06 " \mathrm{~N}-73^{\circ} 17^{\prime} 12.40^{\prime \prime O}$ & \\
\hline BRAb & Balneario Rincón aguas abajo & $10^{\circ} 30^{\prime} 25.27 " \mathrm{~N}-73^{\circ} 16^{\prime} 50.46 " \mathrm{O}$ & \\
\hline BVAr & Balneario La Vega aguas arriba & $10^{\circ} 40^{\prime} 8.46 " \mathrm{~N}-73^{\circ} 13^{\prime} 18.50 " \mathrm{O}$ & \multirow{2}{*}{ Río Badillo } \\
\hline BVAb & Balneario La Vega aguas abajo & $10^{\circ} 39^{\prime} 35.59 " \mathrm{~N}-73^{\circ} 11^{\prime} 44.72 " \mathrm{O}$ & \\
\hline BMAr & Balneario El Mojao aguas arriba & $10^{\circ} 42^{\prime} 14.82 " \mathrm{~N}-73^{\circ} 19^{\prime} 28.78 " \mathrm{O}$ & \multirow{2}{*}{ Río Candela } \\
\hline BMAb & Balneario El Mojao aguas abajo & $10^{\circ} 42^{\prime} 0.91 " \mathrm{~N}-7^{\circ} 19^{\prime} 24.94^{\prime \prime O}$ & \\
\hline
\end{tabular}

\section{Determinación de bacterias del grupo coliformes}

La determinación del grupo coliformes se realizó utilizando la técnica de filtración por membrana y teniendo en cuenta lo establecido en el protocolo del Instituto de Hidrología, Meteorología y Estudios Ambientales (IDEAM, 2007). Las muestras fueron procesadas en un equipo de filtración con bomba de vacío, utilizando membranas de $0,45 \mu \mathrm{m}$ de nitrocelulosa (Sartorius), las membranas fueron depositadas con pinzas estériles en cajas de Petri con agar Chromocult (Merck) e incubadas a 37으 por 24-48 horas; Luego del periodo de incubación se seleccionaron las cajas con conteos inferiores a 200 UFC; añadiendo una gota de reactivo de Kovac sobre la colonia ayuda a la confirmación de la presencia de coliformes termotolerantes (FragosoCastilla et al., 2021). Las colonias presuntivas de E colise confirmaron utilizando el método IMVIC (Indol, Rojo de metilo, Voges-Proskauer, Citrato).

\section{Determinación de variables físicas y químicas}

Se determinaron las siguientes variables, temperatura (Método electrométrico 2550A), pH (Método electrométrico 2550A) y conductividad (Método conductimétrico 2510A), (IDEAM, 2007).

\section{Análisis de variables.}

La prueba utilizada para determinar la existencia de diferencias estadísticamente significativas entre los valores de similitud entre los grupos de muestras (Factores espacio-temporales: puntos de muestreo y mes de muestreo) fue un Análisis de Similitud (análisis of similarities-ANOSIM), esta técnica es análoga a ANOVA, la cual es utilizada para estadística univariada (análisis de varianza), usando el programa estadístico Past $\AA$, V 3.22. Por último, se realizó por separado un análisis de correlación de Spearman entre los recuentos de Coliformes totales, E. coli con los parámetros fisicoquímicos seleccionados (pH y conductividad eléctrica).

\section{RESULTADOS Y DISCUSIÓN}

Los resultados se presentan en 2 subsecciones: i) caracterización bacteriológica y fisicoquímica; ii) análisis de la información.

\section{Caracterización bacteriológica y fisicoquímica}

De manera general, todos los 8 puntos muestreados durante el periodo de estudio, presentaron índice de coliformes totales y E. coli (Tabla 2), con valores que sobrepasan los valores establecidos en la normatividad Colombiana Ambiental vigente (Decreto 1076 de 2015), el cual reglamenta el uso del agua y los criterios de calidad para la destinación del agua para fines recreativos mediante contacto primario. La concentración promedio más baja de Coliformes totales se presentó en el balneario Hurtado aguas abajo con 5587,5 UFC/100 ml y la más alta en el balneario La Vega aguas abajo con $7232,3 \mathrm{UFC} / 100 \mathrm{ml}$, en cuanto a $E$. coli la concentración más baja se presentó en el balneario Rincón aguas abajo con 1987,5 UFC/100 ml y la más alta con 3125 UFC/100 ml en el balneario El Mojao aguas abajo.

A nivel general la relación de $E$ coli/Coliformes totales es de 0,40 para los sitios muestreados y durante el periodo de estudio. Sin embargo, la relación $E$ coli/Coliformes totales experimenta un incremento al pasar de 0,37 aguas arriba del sitio de ubicación de los bañistas a 0,42 aguas debajo de los balnearios. Según la Agencia de Protección Ambiental de los Estados Unidos (USEPA) una relación inferior a 0,63 se presenta como un factor de protección frente a posibles patógenos (USEPA, 2002). A nivel temporal en el mes de diciembre se presentó la concentración más alta de Coliformes totales con una concentración promedio de 7212,5 UFC/100 ml y la más baja se presentó en el mes de enero con 5131,25 UFC/100 ml (Figura 2), en cuanto a $E$. coli la concentración promedio más alta fue en el mes de octubre con 3000 UFC/100 ml y la más baja para el mes de enero con 1750 UFC/100 ml (Figura 3). 
Tabla 2. Variables bacteriológicas en las aguas de los balnearios Hurtado, El Rincón, La vega, El Mojao del municipio de Valledupar- Cesar.

\begin{tabular}{|c|c|c|c|c|c|}
\hline Parámetro & Punto de muestreo & $\begin{array}{c}\text { Balneario El } \\
\text { Mojao }\end{array}$ & $\begin{array}{l}\text { Balneario La } \\
\text { Vega }\end{array}$ & $\begin{array}{l}\text { Balneario } \\
\text { Hurtado }\end{array}$ & $\begin{array}{l}\text { Balneario } \\
\text { El Rincón }\end{array}$ \\
\hline \multirow{8}{*}{$\begin{array}{l}\text { Coliformes Totales } \\
\text { (UFC)/100 ml }\end{array}$} & \multirow{4}{*}{ Rio Arriba } & 6050 & 4750 & 6100 & 3850 \\
\hline & & 6650 & 5350 & 7050 & 4900 \\
\hline & & 5100 & 5150 & 7300 & 4400 \\
\hline & & 6650 & 5550 & 6500 & 4100 \\
\hline & \multirow{4}{*}{ Rio Abajo } & 7659 & 6700 & 7800 & 5600 \\
\hline & & 8700 & 6800 & 8650 & 5950 \\
\hline & & 8150 & 6850 & 8400 & 6100 \\
\hline & & 7950 & 6700 & 5900 & 6150 \\
\hline \multirow{8}{*}{$\begin{array}{l}\text { E. coli } \\
\text { (UFC)/100 ml }\end{array}$} & \multirow{4}{*}{ Rio Arriba } & 2250 & 2350 & 2600 & 1150 \\
\hline & & 2900 & 2450 & 2250 & 1350 \\
\hline & & 3150 & 2050 & 1550 & 1400 \\
\hline & & 2900 & 2350 & 1300 & 1200 \\
\hline & \multirow{4}{*}{ Rio Abajo } & 3200 & 3150 & 2750 & 2350 \\
\hline & & 3350 & 3350 & 3400 & 2150 \\
\hline & & 3050 & 3650 & 3500 & 2150 \\
\hline & & 3200 & 3700 & 3500 & 2250 \\
\hline
\end{tabular}

Tabla 3. Relación de E coli y Coliformes totales en las aguas de los balnearios Hurtado, El Rincón, La vega, El Mojao del municipio de Valledupar- Cesar.

\begin{tabular}{|c|c|c|c|c|}
\hline Punto de muestreo & Balneario El Mojao & Balneario La Vega & Balneario Hurtado & Balneario El Rincón \\
\hline \multirow{3}{*}{ Rio Arriba } & 0,37 & 0,49 & 0,43 & 0,30 \\
\cline { 2 - 5 } & 0,44 & 0,46 & 0,32 & 0,28 \\
\cline { 2 - 5 } & 0,62 & 0,40 & 0,21 & 0,32 \\
\cline { 2 - 5 } & 0,44 & 0,42 & 0,20 & 0,29 \\
\hline \multirow{3}{*}{ Rio Abajo } & 0,42 & 0,47 & 0,35 & 0,42 \\
\cline { 2 - 5 } & 0,39 & 0,49 & 0,39 & 0,36 \\
\cline { 2 - 5 } & 0,37 & 0,53 & 0,42 & 0,35 \\
\cline { 2 - 5 } & 0,40 & 0,55 & 0,59 & 0,37 \\
\hline
\end{tabular}

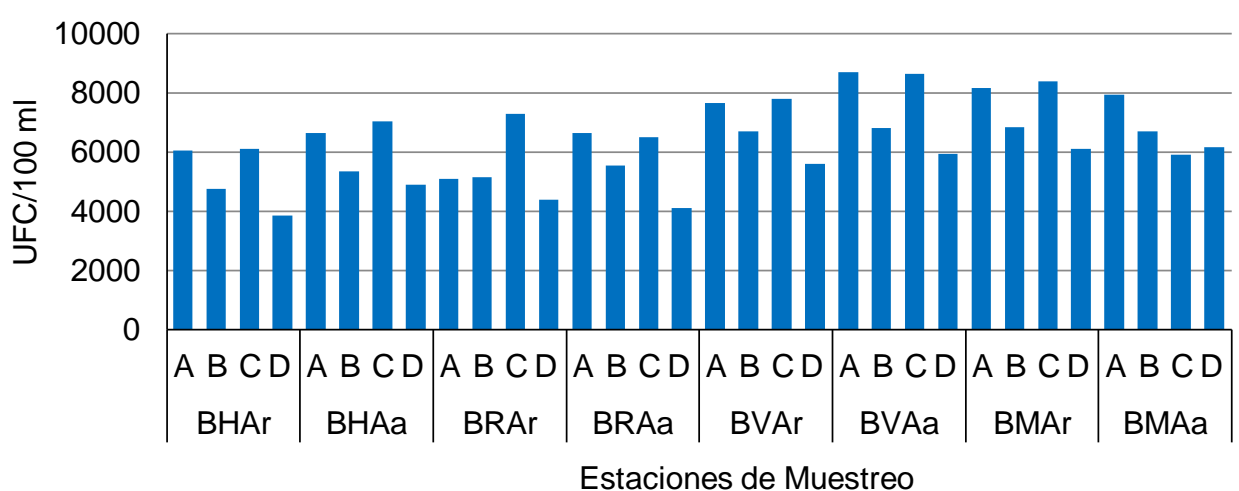

- Coliformes totales

A octubre

B noviembre

C diciembre

$\mathrm{D}$ enero

Fig. 2: Distribución de UFC/100 $\mathrm{ml}$ de Coliformes totales en los balnearios Hurtado, El Rincón, La Vega y El Mojao del municipio de Valledupar-Cesar.

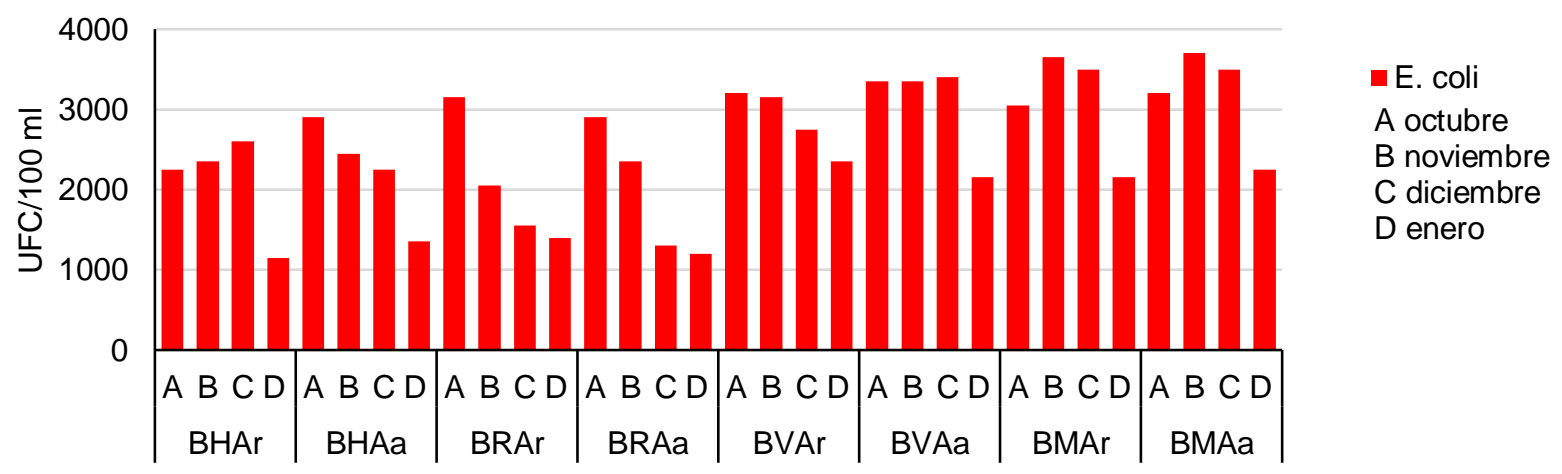

Estaciones de Muestreo

Fig. 3: Distribución de UFC/100 ml de E. coli en los balnearios Hurtado, El Rincón, La Vega y EI Mojao del municipio de Valledupar-Cesar. 
La (Tabla 4) muestra los valores de los parámetros fisicoquímicos evaluados in situ se evidencia que los valores de $\mathrm{pH}$ de los sistemas hídricos a nivel espacio-temporal mantuvieron una tendencia hacia la neutralidad, comprendiendo valores que oscilan entre 6,13-7,5 U de pH a $25^{\circ} \mathrm{C}$. El valor de $\mathrm{pH}$ más bajo se registró en el balneario el rincón y el más alto en el balneario hurtado. El rango de pH que brinda protección a la vida acuática debe ser de 6.0 a 9.0, por lo que, los valores de pH obtenidos se encuentran dentro de este; además no constituyen un riesgo de daño a nivel cutáneo de las personas que entran en contacto con ellas (Maranho et al., 2014). Este comportamiento es debido principalmente a una circulación permanente de las fuentes hídricas en estos sitios turísticos. En cuanto a los valores de, conductividad, se encontraron valores entre 35 y $92,5 \mu \mathrm{S} / \mathrm{cm}$, lo que demuestra un bajo contenido de sales disueltas. El balneario La Vega reporto los valores más bajos con un promedio de $36,8 \mu \mathrm{S} / \mathrm{cm}$, mientras que el balneario Hurtado reporto valores más elevados con un promedio de $64,1 \mu \mathrm{S} / \mathrm{cm}$.

Tabla 4. Variables fisicoquímicas evaluados in situ en los balnearios Hurtado, El Rincón, La Vega y El Mojao del municipio de Valledupar-Cesar.

\begin{tabular}{|c|c|c|c|c|c|c|}
\hline Parámetro & Lugar & Mes & $\begin{array}{c}\text { Balneario El } \\
\text { Mojao }\end{array}$ & $\begin{array}{c}\text { Balneario } \\
\text { La Vega }\end{array}$ & $\begin{array}{c}\text { Balneario } \\
\text { Hurtado }\end{array}$ & $\begin{array}{c}\text { Balneario El } \\
\text { Rincón }\end{array}$ \\
\hline \multirow{8}{*}{ 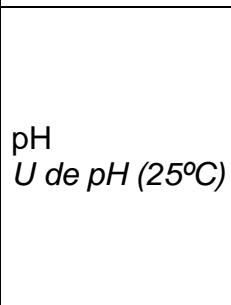 } & \multirow{4}{*}{ Rio Arriba } & octubre & 7,42 & 7,04 & 7,5 & 6,13 \\
\hline & & noviembre & 6,97 & 6,75 & 6,97 & 7,12 \\
\hline & & diciembre & 7,06 & 7 & 6,98 & 7,22 \\
\hline & & enero & 7,33 & 7,05 & 7,04 & 7,17 \\
\hline & \multirow{4}{*}{ Rio Abajo } & octubre & 7,4 & 7,12 & 7,4 & 7,43 \\
\hline & & noviembre & 6,69 & 6,86 & 7,2 & 7,27 \\
\hline & & diciembre & 6,72 & 6,76 & 7,2 & 7,37 \\
\hline & & enero & 7.03 & 6.95 & 7.04 & 7,3 \\
\hline \multirow{8}{*}{$\begin{array}{l}\text { Conductividad } \\
\mu \mathrm{s} / \mathrm{cm}\end{array}$} & \multirow{4}{*}{ Rio Arriba } & octubre & 92 & 35,5 & 45,5 & 46 \\
\hline & & noviembre & 52,5 & 39 & 53,5 & 47 \\
\hline & & diciembre & 52 & 38,5 & 49,5 & 43,5 \\
\hline & & enero & 53 & 40 & 52,2 & 46,5 \\
\hline & \multirow{4}{*}{ Rio Abajo } & octubre & 92,5 & 35 & 46 & 46 \\
\hline & & noviembre & 57 & 37,5 & 49,5 & 47 \\
\hline & & diciembre & 53,5 & 31,5 & 49 & 44,5 \\
\hline & & enero & 60,5 & 37,5 & 50 & 46 \\
\hline
\end{tabular}

El análisis de correlación de Spearman ( $\rho$ ) acompañado del nivel de significancia (p) (significativo cuando es $<0,05$ ) entre los parámetros fisicoquímicos ( $\mathrm{pH}$ y conductividad eléctrica) y los niveles de Coliformes totales y E. coli evaluados en cada uno de los balnearios y mes de muestreo (Tabla 5), determinaron que no existe una relación directa (relación inversa o indirecta) ni una correlación significativa ( $p>0.05)$ entre las variables; excepto para las variables $\mathrm{pH}$-E.coli en el mes de diciembre que tuvo una correlación significativa $(p<0.05)$.

Tabla 5. Análisis estadístico entre pares de variables por el método de correlación de Spearman

\begin{tabular}{|l|c|c|c|c|c|c|c|c|}
\hline \multirow{2}{*}{ Mes } & \multicolumn{2}{|c|}{$p H$ - Coliformes totales } & \multicolumn{2}{c|}{$p H$ - E. coli } & \multicolumn{2}{c|}{ Conductividad - Coliformes totales } & \multicolumn{2}{c|}{ Conductividad - E. coli } \\
\cline { 2 - 10 } & Correlación & $p$-valor & Correlación & $p$-valor & Correlación & $p$-valor & Correlación & $p$-valor \\
\hline octubre & $-0,0422$ & 0,911 & $-0,727$ & 0,054 & $-0,024$ & 0,948 & $-0,197$ & 0,601 \\
\hline noviembre & $-0,4578$ & 0,225 & $-0,704$ & 0,062 & $-0,216$ & 0,566 & 0,234 & 0,534 \\
\hline diciembre & 0,071 & 0,850 & $-0,79$ & 0,036 & $-0,619$ & 0,101 & 0,371 & 0,326 \\
\hline enero & $-0,227$ & 0,547 & $-0,156$ & 0,678 & 0,261 & 0,488 & $-0,071$ & 0,849 \\
\hline
\end{tabular}

\section{Análisis de la información}

Los recuentos de los grupos de bacterias Coliformes totales no mostraron diferencias estadísticamente significativas entre las estaciones de los balnearios estudiados (ANOSIM, test global, R= 0,501, p>0.05); mientras que los recuentos de $E$. coli mostraron diferencias estadísticamente significativas entre las estaciones de los balnearios estudiados (ANOSIM, test global, $\mathrm{R}=0,739, p<0.05$ ). A escala temporal las muestras recolectadas arrojaron diferencias estadísticamente significativas entre los meses de muestreo para los Coliformes totales (ANOSIM, test global, $\mathrm{R}=0.178, \quad p<0.05$ ); las diferencias más significativas se presentaron entre los meses de octubre-enero $(p=0,004)$ y diciembre-enero $(p=0,001)$. Para $E$. coli las muestras recolectadas arrojaron diferencias estadísticamente significativas entre los meses de muestreo (ANOSIM, test global, $\mathrm{R}=0,230, p<0.05$ ); las diferencias más significativas se presentaron entre los meses de octubre-enero $(p=0,0002)$, noviembre-enero $(p=0,002)$ y diciembre-enero $(p=0,027)$.

En comparación con los estudios de Zhao et al., (2018) y Tian et al., (2019), afirman que la concentración de coliformes totales varía entre los muestreos realizados en las diferentes temporadas del año (secas y lluvia), haciendo notar que la presencia de coliformes está en función del aporte de sedimentos de los terrenos aledaños al cuerpo de agua lo que hace que la densidad del número de microorganismo aumente o disminuya. 
Las condiciones climatológicas correspondiente a los meses de noviembre y diciembre fueron condiciones de periodo seco, sin precipitaciones; Lo cual, pudo ocasionar el aumento en la concentración de coliformes totales y $E$ coli en los diferentes balnearios objeto de estudio (Bojarczuk et al., 2018). Los muestreos realizados en los meses de septiembre y octubre equivalen a periodos lluviosos, lo que contribuyó al arrastre de sedimentos hacia las corrientes principales, a pesar de que se pudo presentar una mayor concentración de coliformes por el arrastre de contaminación bacteriológica debido al escurrimiento de las precipitaciones, estos meses tuvieron menos densidad bacteriológica, siendo esto un fenómeno que coincide con el trabajo de Ospina-Zuñiga y Moyano-Diaz (2015) y Alexander et al., (2018).

Según, Gleason y Fagliano (2017) los resultados de coliformes en muestras de agua, dependen mucho de las condiciones hidrometeorológicas y de las actividades humanas. Agregado a eso, la existencia de bacterias coliformes autóctonas, que cumplen funciones específicas en los cuerpos de agua, por ello los resultados varían al repetirse las pruebas, así como sucedió en el presente estudio de acuerdo al lugar y al sitio de muestreo. El agua de los balnearios el Mojao, La Vega, Hurtado y El Rincón, presenta contaminación biológica por bacterias del grupo coliformes originadas por descargas de aguas residuales, así como también el arrastre y escurrimiento ocasionado por las lluvias de materia del suelo. El consumo directo de estas aguas puede ocasionar repercusiones en la salud humana, como el desarrollo de enfermedades gastrointestinales, además el contacto directo puede conllevar a otras enfermedades en la piel, las mucosas entre otras (Lara y García, 2019).

Las proporciones de $E$ coli y Coliformes totales (40\%) registradas en los sitios muestreados evidencian una posible contaminación de origen antropológico (Larrea-Murrell et al., 2013). Sin embargo, según la USEPA, se considera riesgo para la salud una relación superior al $60 \%$ de $E$ coli. Aunque para tener en cuenta estos referentes tambien es importante considerar la zona de estudio, el medio acuatico y las tecnicas de analisis empleadas. Las determinaciones de $\mathrm{pH}$ y Conductividad eléctrica analizadas en los balnearios Hurtado, Rincón, La Vega y El Mojao durante los meses de muestreo, demostraron tendencias similares para los cauces. Posiblemente esto se deba a que los sistemas hídricos que nacen en estribaciones de la Sierra Nevada de Santa Marta guardan comportamientos de similitud desde el punto de vista geográfico, socioeconómico y cultural, por tanto, se considera que los parámetros fisicoquímicos y bacteriológicos analizados constituyen una base para sistemas de bioindicación y dictamen de la calidad sanitaria del recurso hídrico de este sistema montañoso.

Con respecto al pH los valores mantuvieron una estabilidad hacia la neutralidad probablemente por el poco aporte de sustancias que alteren esta variable. La conductividad eléctrica del agua en las ocho estaciones de muestreo fue baja, lo cual indica una homogeneidad y estabilidad del sistema hídrico en cuanto a concentraciones de iones (sólidos disueltos). Los análisis de correlación entre los parámetros fisicoquímicos ( $\mathrm{pH}$ y conductividad eléctrica) con la presencia de Coliformes totales y E. coli en los cuerpos de agua estudiados determinaron que no existe una correlación entre las variables químicas y microbiológicas analizadas. Este hecho coincide con lo reportado por Fragoso-Castilla et al., (2021) en un estudio de correlación entre las variables físico-químicas y el proceso de remoción de coliformes en un sistema de lagunas de oxidación en el Departamento de Cesar - Colombia y difieren de los resultados obtenidos Romero et al., (2010). En un estudio realizado en el Río Hardy en la región fronteriza México-Estados Unidos, donde reporta una correlación altamente significativa entre la conductividad eléctrica y la concentración de $E$. coli $(\mathrm{P}<0.001)$.

En este estudio las aproximaciones que se realizaron a la calidad del agua de los ríos Guatapurí, Badillo y Candela se basaron de acuerdo a lo establecido en la normatividad colombiana, presentando en todos sus puntos de muestreos contaminación por Coliformes totales y E. coli, lo que imposibilita que el recurso hídrico pueda ser aprovechado para el consumo directo por los asentamientos humanos aledaños a la cuenca. Sin embargo, según lo establecido en el Decreto 1076 de 2015 del Ministerio de Ambiente y Desarrollo sostenible - Colombia.

\section{CONCLUSIONES}

Los estudios a nivel de campo y laboratorio permiten afirmar lo siguiente: 1) Las concentraciones de Coliformes totales y E. coli en las aguas de los balnearios Hurtado, El Rincón, La vega, El Mojao del municipio de Valledupar sobrepasan lo estipulado en la normatividad ambiental vigente para uso recreativo mediante contacto primario. 2) Las altas concentraciones de Coliformes totales y E. coli se debe a la introducción y descomposición de residuos de origen antropogénico en las zonas de estudio. 3) La proporción $E$ coli/coliformes puede ser utilizada como una herramienta de monitoreo para estos balnearios.

\section{AGRADECIMIENTOS}

Los autores reconocen la ayuda de laboratorios BIOINDALAMB, laboratorio de análisis químico, clínico en Valledupar - Cesar. Al programa de Microbiología de la Universidad Popular del Cesar, Colombia y el apoyo logístico realizado por La Empresa de Servicios Públicos de Valledupar - Cesar. EMDUPAR S.A. ESP. 


\section{REFERENCIAS}

Alexander, K. A., Heaney, A. K., y Shaman, J., Hydrometeorology and flood pulse dynamics drive diarrheal disease outbreaks and increase vulnerability to climate change in surface-water-dependent populations: A retrospective analysis, http://doi.org/10.1371/journal.pmed.1002688, PLoS medicine, 15(11) (2018)

Ashbolt, N. J., Microbial contamination of drinking water and human health from community water systems. Current environmental health reports, 2(1), 95-106 (2015)

Barragán, J. M., y De Andrés, M., Expansión urbana en las áreas litorales de América Latina y Caribe. Revista de Geografía Norte Grande, (64), 129-149 (2016)

Bojarczuk, A., Jelonkiewicz, Ł., y Lenart-Boroń, A., The effect of anthropogenic and natural factors on the prevalence of physicochemical parameters of water and bacterial water quality indicators along the river Białka, southern Poland, http://doi.org/10.1007/s11356-018-1212-2, Environmental science and pollution research international, 25(10), 1010210114 (2018)

De Florio-Barker, S., Wing., y otros 2 autores. Estimate of incidence and cost of recreational waterborne illness on United States surface waters. http://doi.org/10.1186/s12940-017-0347-9, Environmental Health, 17(1), 3. (2018)

Fernández, L., y Gutiérrez, M., Bienestar social, económico y ambiental para las presentes y futuras generaciones, http://.org.doi/10.4067/S0718-07642013000200013, Información tecnológica, 24(2), 121-130 (2013)

Fragoso-Castilla, P. J., Rubiano, L. A., y Kerguelen, J. J. Análisis de variables físico-químicas en el proceso de remoción de coliformes en el sistema de lagunas de oxidación, Salguero, Valledupar (Colombia), http://dx.doi.org/10.4067/S071807642021000100113. Información tecnológica, 32(1), 113-122. (2021)

Gleason, J.A., y Fagliano, J. A., Effect of drinking water source on associations between gastrointestinal illness and heavy rainfall in New Jersey, http://doi.org/10.1371/journal.pone.0173794, PloS one, 12(3) e0173794 (2017)

Instituto de Hidrología, Meteorología y Estudios Ambientales (IDEAM)., Guía para el monitoreo y seguimiento del agua. Bogotá (2007)

Islam, M. M., Sunny, A., y otros 2 autores., Drivers of mangrove ecosystem service change in the Sundarbans of Bangladesh, https://doi.org/10.1111/sjtg.1224, Singapore Journal of tropical geography, 39(2), 244-265. (2018)

Kacar, C., Analysis of spatial and temporal variation in the levels of microbial fecal indicators in the major rivers flowing into the Aegean Sea, http://doi.org/10.1016/j.ecolind.2011.02.010, Turkey.Ecological Indicators, 11, 1360- 1365 (2011)

Korajkic, A., McMinn, B. R., y Harwood, V. J., Relationships between microbial indicators and pathogens in recreational water settings, http://doi.org/10.3390/ijerph15122842, International Journal of Environmental Research and Public Health, 15(12), 2842 (2018)

Larrea-Murrell, J. A., Rojas-Badía, M. M., y otros 3 autores, Bacterias indicadoras de contaminación fecal en la evaluación de la calidad de las aguas: revisión de la literatura. Revista CENIC. Ciencias Biológicas, 44(3), 24-34. (2013)

Maranho, L.A., Maranho, L.T., Botelho, R.G. y Tornisielo, V.L., Dissolved heavy metal determination and ecotoxicological assessment: a case study of the Corumbataí River (São Paulo, Brazil), http://doi.org/10.2478/10004-1254-65-2014-255, Archives of Industrial Hygiene and Toxicology, 65(3), 319-328 (2014)

Olalekan, R. M., Omidiji, A., y otros 3 autores, The roles of all tiers of government and development partners in environmental conservation of natural resource: a case study in Nigeria, http://doi.org/10.15406/mojes.2019.04.00142, MOJ Ecology \& Environmental Sciences, 4(3), 114-121. (2019)

Ospina-Zúñiga, O.E. y Moyano-Díaz, Y.C., Evaluación del aprovechamiento para consumo humano del agua de lluvia en una microcuenca urbana de Ibagué, Tolima, Colombia. (2015)

Romero, S., García, J., y otros 2 autores, Calidad del agua para actividades recreativas del Río Hardy en la región fronteriza México-Estados Unidos. http://dx.doi.org/10.4067/S0718-07642010000500010, Información tecnológica, 21(5), 69-78 (2010).

Steiner, T.S., Thielman N.M., y Guerrant R.L., Protozoal agents. What are the dangers for the public water-supply. Annu, http://doi.org/10.1146/annurev.med.48.1.329, Rev Med. 48:329-340 (1997)

Tian, H., Yu, G.A., y otros cinco autores, Water Quality of the Mun River in Thailand-Spatiotemporal Variations and Potential Causes, http://doi.org/10.3390/ijerph16203906, International journal of environmental research and public health, 16(20) 3906 (2019)

Ustaoğlu, F., Tepe, Y., y Taş, B. Assessment of stream quality and health risk in a subtropical Turkey river system: A combined approach using statistical analysis and water quality index, https://doi.org/10.1016/j.ecolind.2019.105815, Ecological Indicators, 105815 (2019)

Williamson, C. E., Madronich, S., y otros 7 autores, Climate change-induced increases in precipitation are reducing the potential for solar ultraviolet radiation to inactivate pathogens in surface waters, Scientific Reports, 7(1), 1-12. (2017)

Zhao, Z., Liu, G., y otros tres autores., Studies on the Spatiotemporal Variability of River Water Quality and Its Relationships with Soil and Precipitation: A Case Study of the Mun River Basin in Thailand, http://doi.org/10.3390/ijerph15112466, International journal of environmental research and public health, 15(11) 2466 (2018) 